\title{
Assessing uncertainty of climate change impacts on long-term hydropower generation using the CMIP5 ensemble - the case of Ecuador
}

\author{
Pablo E. Carvajal ${ }^{1}$ • Gabrial Anandarajah ${ }^{1}$. \\ Yacob Mulugetta ${ }^{2} \cdot$ Olivier Dessens $^{1}$
}

Received: 7 January 2017 / Accepted: 3 August 2017 / Published online: 15 August 2017

(C) The Author(s) 2017. This article is an open access publication

\begin{abstract}
This study presents a method to assess the sensitivity of hydropower generation to uncertain water resource availability driven by future climate change. A hydrology-electricity modelling framework was developed and applied to six rivers where 10 hydropower stations operate, which together represent over $85 \%$ of Ecuador's installed hydropower capacity. The modelling framework was then forced with bias-corrected output from 40 individual global circulation model experiments from the Coupled Model Intercomparison Project 5 for the Representative Concentration Pathway 4.5 scenario. Impacts of changing climate on hydropower resource were quantified for 2071-2100 relative to a baseline period 1971-2000. Results show a wide annual average inflow range from $+277 \%$ to $-85 \%$ when individual climate experiments are assessed. The analysis also show that hydropower generation in Ecuador is highly uncertain and sensitive to climate change since variations in inflow to hydropower stations would directly result in changes in the expected hydropower potential. Annual hydroelectric power production in Ecuador is found to vary between -55 and $+39 \%$ of the mean historical output when considering future inflow patterns to hydroelectric reservoirs covering one standard deviation of the CMIP5 RCP4.5 climate ensemble.
\end{abstract}

Electronic supplementary material The online version of this article (doi:10.1007/s10584-017-2055-4) contains supplementary material, which is available to authorized users.

Pablo E. Carvajal

pablo.carvajal.14@ucl.ac.uk

1 UCL Energy Institute, University College London, Central House 14 Upper Woburn Place, London WC1H 0NN, UK

2 Department of Science, Technology, Engineering and Public Policy, University College London, 36-37 Fitzroy Square, London W1T 6EY, UK 


\section{Introduction}

Hydropower dominates the electricity system in South America, providing $63 \%$ of total electricity generation (van Vliet et al. 2016). This trend is expected to continue into the future. In the Tropical Andes only (the northwest region of South America: Colombia, Ecuador, Peru and Bolivia), there are plans for 151 new dams greater than $2 \mathrm{MW}$ over the next 20 years, more than a 300\% increase (Finer and Jenkins 2012). Ecuador in particular will have a power generation matrix with an expected $90 \%$ share of hydropower by 2017 , with the addition of approximately $2800 \mathrm{MW}$ of new hydropower capacity (ARCONEL 2015). However, future hydropower electricity generation is highly uncertain given variable inter-annual runoff patterns and also due to the possible impacts of climate change, given the considerable discrepancies around the likely change in the magnitude and direction of precipitation in the future (Cisneros et al. 2014). For the Tropical Andes, global circulation models (GCM) run for the Coupled Model Intercomparison Project 5 (CMIP5) forced under the Representative Concentration Pathway (RCP) $4.5^{1}$ project a large variation for precipitation change. The 25 th percentile of models projects a decline in precipitation approaching $-30 \%$, while the 75 th percentile suggests an increase of up to $20 \%$ (April to September) (van Oldenborgh et al. 2013). This spread of results is indicative of the variation in the representation of precipitation among GCMs, hence demonstrating their limitation to consistently represent the behaviour of precipitation in this region.

A number of previous studies quantify impacts of climate change on energy systems at national (CEPAL 2012; Liu et al. 2016), regional (Schaeffer et al. 2013b; DOE 2015) and global level (van Vliet et al. 2016). The magnitude of climate change impacts on hydropower generation is usually assessed by running a baseline calibrated hydrological model driven by various climate projections as input forcing data, followed by an electricity generation model (Hay et al. 2002). To assess uncertainty related to climate change, studies use a combination of emission or concentration scenarios to derive a range of probable results but use only data from a limited number of GCMs, often only the mean value of GCM results is used (Buytaert et al. 2010). For instance, the studies by CEPAL (2012) and De Lucena et al. (2010) assessed vulnerability of hydropower to future climate projections for IPCC's SRES A2 and B2 scenarios $^{2}$ and one GCM (HadCM3) for Chile and Brazil, respectively. Escobar et al. (2011) assessed hydropower generation in Latin America and the Caribbean drawing on projections of average temperature and rainfall throughout the current century for A2 and B2 emission scenarios with the ensemble mean value of GCM results. In comparison, Grijsen (2014) assessed five hydropower river basins in Cameroon using one emission scenario A1B but 15 GCMs. Shrestha et al. (2016) consider the more recent RCP4.5 and RCP8.5 with three GCMs (MIROC-ESM, MRI-CGCM3, and MPI-ESM-M) to assess risk due to climate change for a hydropower project in Nepal. These studies, among others (e.g. Hamlet et al. 2010; Lind et al. 2013; Madani and Lund 2010), highlight the significant sensitivity that hydropower can have to precipitation changes and that the main source of uncertainty for regional climate scenarios is associated with projections of different GCMs, therefore the importance of using several GCMs to assess uncertainty and the growing interest in using large ensembles of GCMs to improve the reliability of future projections.

\footnotetext{
${ }^{1}$ Radiative forcing is stabilised at $4.5 \mathrm{~W} / \mathrm{m}^{2}$ in the year 2100 without ever exceeding this value.

${ }^{2}$ Socio-economic scenarios of the Intergovernmental Panel on Climate Chante Assessment Report 4 (A1, A2, B1, B2, etc.)
} 
The objective of this paper is to assess the impacts of climate change on hydrological patterns and therefore on hydropower generation when using a large ensemble of projections. For this purpose, a hydrologic-electricity model was developed and applied to six rivers in Ecuador where 10 hydropower stations operate, representing over $85 \%$ of the country's hydropower installed capacity. The model was calibrated for a 1971-2000 baseline period, which subsequently was used to assess changes in inflow by forcing it with bias-corrected outputs from 40 CMIP5 GCMs for the period 2071-2100 under the RCP4.5 scenario. The mean and standard deviation of inflow obtained with the CMIP5 ensemble were later used to simulate changes in the capacity factors ${ }^{3}$ and electrical output of hydropower stations. There are a number of novelties in this paper worth noting. Firstly, this study employs a large ensemble of GCMs to cover a wide range of future climate conditions. Secondly, the study uses a simple statistical approach that is not data intensive which can be replicated in data scarce regions. Finally, the uncertainty of the impacts of climate change upon the Tropical Andes has not been systematically investigated, despite the importance for hydropower deployment for the region (Finer and Jenkins 2012). The latest AR5 report of the IPPC insists on the importance of considering uncertainties surrounding climate in supporting national adaptation and mitigation strategies, and recognises the lack of consistent tools to deal with these uncertainties (Cisneros et al. 2014; IPCC 2014)

\section{Methods}

To undertake this analysis, we obtain inflow time series for 10 hydropower stations in Ecuador using historic inflow values and gridded projected climate data to force a conceptual hydrological model. Next, we compile data describing the technical specifications of the selected hydropower plants and develop a model to simulate monthly hydropower electricity production. For hydropower stations that have storage capacity (reservoir), we assign a bespoke operating policy according to historic values that provide a realistic basis for water release decisions that affect hydropower production. These steps are detailed in the following subsections.

\subsection{Study area and data}

Ecuador is located in the northwest part of South America in the region known as the Tropical Andes (see Fig. 1). The Andes define the hydrographical system of the country and its river basins: the Pacific watershed that discharges into the Pacific Ocean and the Amazon watershed which consists of main tributaries to the Amazon river. Overall, spatial precipitation patterns are highly variable, with annual precipitation ranging from over $3000 \mathrm{~mm}$ in the Amazonian slopes to less than $500 \mathrm{~mm}$ in the southwest part of the country (Buytaert et al. 2011), while seasonal variability ranges from $350 \mathrm{~mm} /$ month in the rainy season to lower than $100 \mathrm{~mm} /$ month in the dry season (Espinoza Villar et al. 2009). ${ }^{4}$ In this study, six large rivers that are

\footnotetext{
${ }^{3}$ The capacity factor of a power plant is the ratio of its actual output over a period of time, to its potential output if it were possible for it to operate at full nameplate capacity continuously over the same period of time.

${ }^{4}$ Even though small glaciers are present in the Ecuadorian Andes, strong solar radiation precludes the development of a seasonal snow cover. Snowmelt therefore does not provide an additional, seasonally-changing water reservoir, meaning that precipitation and evapotranspiration remain the leading hydroclimatic drivers (Kaser et al. 2003; Vergara et al. 2007; Kaser et al. 2010)
} 
relevant for hydropower generation are represented. Three of these rivers belong to the Pacific watershed: Toachi, Daule and Jubones, while three belong to the Amazon watershed: Paute, Agoyán and Coca (see Fig. 1).

Hydropower installed capacity in Ecuador reached 4382 MW in November in 2016, which represents $58 \%$ of the total installed capacity $(7587 \mathrm{MW})$, the remaining percentage provided by gas and fuel-based thermoelectric plants (40\%) and non-conventional renewables $(2 \%)$ (solar, wind, biomass and small hydro) (ARCONEL 2016). There is one national interconnected electricity grid system, which transmits centralised power generation to consumption centres in the country. Hydropower's share in the power generation matrix is currently $65 \%$ $(15,264 \mathrm{GWh} /$ year) and is expected to reach over $90 \%$ by 2017 (> 21,000 GWh/year) with new large-scale hydropower projects led by the government (Zambrano-Barragen 2012; ARCONEL 2015). Coca Coda Sinclair (1500 MW) is the largest among these new projects, a runoff facility located in the Coca River (Napo basin), which was recently inaugurated in late 2016 (El Comercio 2016). The latest National Energy Agenda 2016-2040 states that there is still large untapped hydropower potential estimated in 22 GW (MICSE 2016), thus supporting the country's long-term objective of continuing to harness this resource and consolidate the power matrix based primarily on hydropower.

The study will assess Ecuador's 10 largest hydropower stations ( 7 in operation and 3 under construction) that together will represent over $85 \%$ of the country's installed hydropower capacity and represent different types of hydropower configuration systems, namely run-of-river/dam and single/cascading systems. Technical characteristics of these facilities including head, usable storage, design flow rate, efficiency and observed mean monthly flow (1971-2000) and electricity production were provided by the Ecuadorian electricity grid operator (CENACE). Streamflow-gauging stations are considered to characterise the

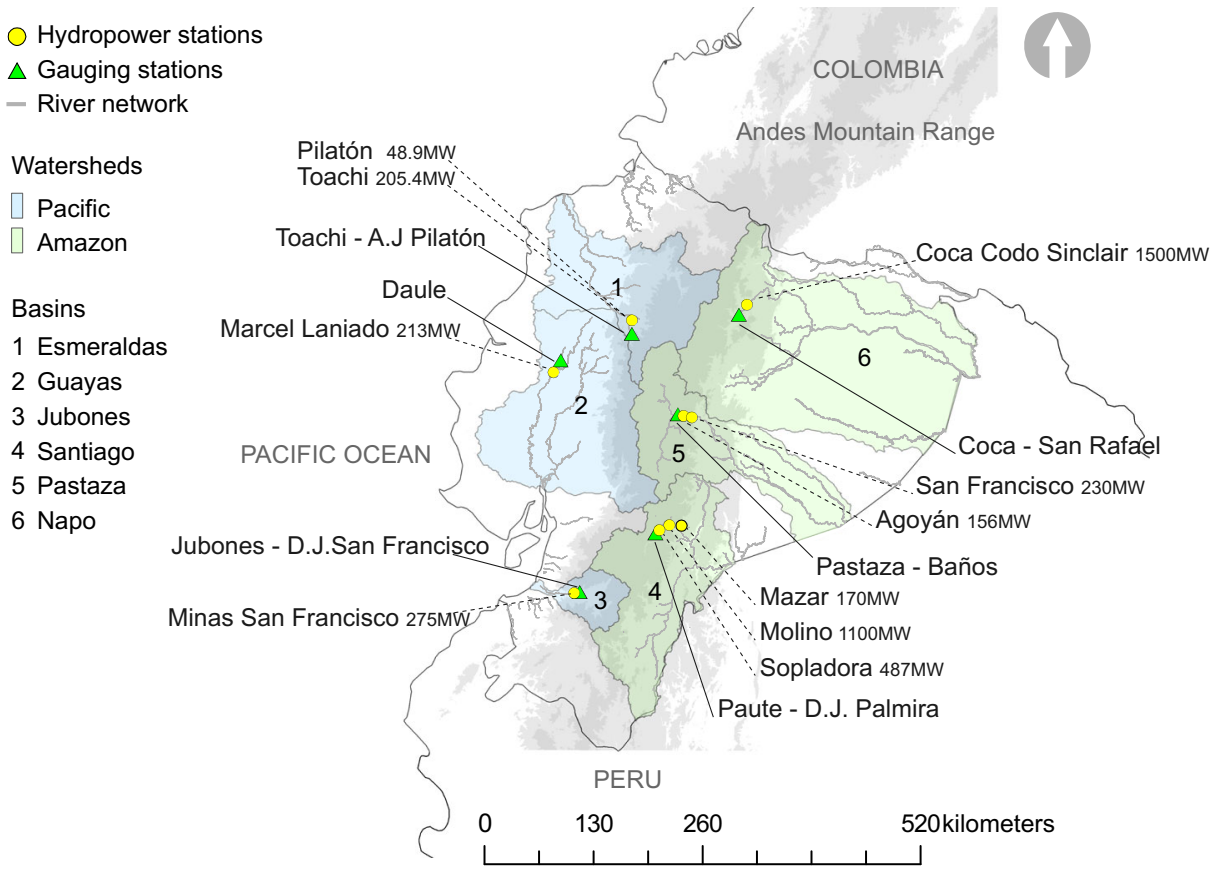

Fig. 1 Ecuador's six major river basins, hydropower stations and gauging stations used in this study 
catchment basin, which is a necessary simplification due to the lack of historic datasets of inflow that cover larger areas of the catchment. Details of each hydropower power station are summarised in the Supplementary Material.

Observed historic monthly mean temperature, precipitation and potential evapotranspiration (PET) for Ecuador for a 30-year period (1971-2000) were extracted from the dataset of the University of East Anglia Climate Research Unit CRU TS v.3.24 (Harris et al. 2014) from the release of October 2016. The gridded data set has a resolution of $0.5^{\circ} \times 0.5^{\circ}$, and the studied river basins lie within 65 grid cells.

Regarding data for climate change projections, GCMs results under the RCP2.6, RCP4.5 and RCP8.5 scenario from the CMIP5 were downloaded from the Royal Netherlands Meteorological Institute (KNMI) Climate Explorer database (see the Supplementary Material for a list of models used) (Trouet and Van Oldenborgh 2013). Monthly precipitation and PET data for each GCM were obtained for the six basins using a bilinear interpolation approach and for two 30-year periods: baseline 1971-2000 and future 2071-2100, against which baseline period values were compared by simple scaling, i.e. the delta factor approach (Fowler et al. 2007). Data was bias-corrected using precipitation and PET values from the observed baseline period CRU datasets and using a multiplier on a monthly basis (Babur et al. 2016). This paper uses only the RCP4.5 scenario for the uncertainty analysis. The reasons to present results only for the RCP4.5 scenario is that (i) it gathers the largest number of GCMs i.e. 41, compared to 26 for the RCP2.6 and 30 for the RCP8.5, (ii) results showed that inter-RCP scenario differences were smaller compared to inter-GCM differences; inter-GCM uncertainty range was also found to have similar magnitude for all three concentration scenarios. In addition, the RCP4.5 is the scenario which approximately conforms with a medium condition of future climate impact (Thomson et al. 2011) and also represents the $2{ }^{\circ} \mathrm{C}$ above pre-industrial values by 2100 , which is the central aim of the United Nations 2015 Paris Agreement.

\subsection{Hydrological model}

For the hydrological component, a conceptual hydrological model consisting of a two-step approach similar to De Lucena et al. (2009), was selected to assess the sensitivity of runoff to climate change precipitation projections. The argument for this type of model over more complex physical models, such as distributed models (Vetter et al. 2015), is that application of these latter can be challenging since their inputs can be difficult to acquire in developing countries especially in the spatially continuous manner, thus hindering the calibration and validation process (Babur et al. 2016). Intercomparison between catchment basins is also made possible with conceptual models since historical precipitation and temperature values are more likely to exist for a larger number of basins (De Lucena et al. 2009). The first step uses 30 years of observed monthly time series of precipitation and inflow to assess the relationship between rainfall and inflow in each hydropower station through a logarithmic linear regression model $^{5}$ (Jones et al. 2006) represented by the following equation:

$$
\ln \left(Q_{t}\right)=\alpha+\beta_{1} \ln \left(\operatorname{Pr}_{t-m}\right)+\beta_{2} d_{2} \ln \left(\operatorname{Pr}_{t-m}\right)+\varepsilon
$$

\footnotetext{
${ }^{5}$ Precipitation has been identified as the leading driver for inflow in Ecuador (Célleri 2007). In regions with little or no snow, e.g. in the Amazon, changes in runoff are much more dependent on changes in rainfall than on changes in temperature (Bates et al. 2008).
} 
where, $Q_{m}$ and $P r_{t-m}$ are the average observed monthly inflow and precipitation (1971-2000) for month $t,{ }^{6} \alpha, \beta_{1}, \beta_{2}$ are the estimated regression coefficients , $d_{2}$ is a categorical variable, ${ }^{7}$ and $\varepsilon$ is the error term. The relevant regression coefficients are $\beta_{1}$ and $\beta_{2}$, which represent the sensitivity or 'elasticity' of average monthly inflow with respect to average precipitation $\left(E_{Q-}\right.$ $\left.{ }_{P r}\right)$. When a month is in the $\mathrm{d}_{2}$ period, the elasticity $E_{Q-P r}$ is equal to $\left(\beta_{1}+\beta_{2}\right)$, otherwise, it is equal to $\beta_{1}$.

In the first step, the seasonal patterns are captured statistically but evapotranspiration and storage effects are omitted, so an additional step is included to correct for total annual discharge. The second step therefore includes the conceptual equation of the water balance: $W B=\operatorname{Pr}-P E T+\triangle S$, where $W B$ is the water balance, $P r$ is precipitation, $P E T$ is potential evapotranspiration and $\Delta S$ is storage variation in soil and underground aquifers that throughout the seasonal cycle can be negligible since the dry period presents negative values and the wet period presents positive values of similar magnitude (Arnold et al. 1998). Future runoff is simulated with the following equation:

$$
Q_{t}^{\text {future }}=Q_{t}^{\text {baseline }} \cdot\left[1+E_{Q-P r} \cdot\left(\Delta \operatorname{Pr}_{t}^{\text {future,baseline }}-1\right)\right] \cdot \phi_{W B, t}
$$

where, $Q_{t}^{\text {future }}$ is the projected inflow for month $t$ for a specific GCM for the future period 2071-2100; $Q_{t}^{\text {baseline }}$ is the observed inflow for the baseline period 1971-2000; $E_{Q-\operatorname{Pr}}$ is the inflow-precipitation elasticity; $\Delta P r_{t}^{\text {future/baseline }}$ is the precipitation delta factor for projected future GCM and baseline and $\phi_{W B, t}$ is the water balance correction factor for a specific month. Hydrological model performance has been validated with a ratings approach similar to that adopted by Ho et al. (2015) which calculate three statistical measures: (i) Pearson's correlation coefficient (r), (ii) Nash-Sutcliffe Efficiency (NSE) coefficient and (iii) percentage deviation (Dv) of simulated mean flow from observed mean flow.

\subsection{Hydropower electricity model}

Once scenarios of runoff were obtained, the approach taken to quantify the variation of hydropower output is calculated considering the site-specific potential energy of available runoff (head) and facility-level configuration of hydropower stations. To simulate the behaviour of the hydropower dam operators (Yi Ng et al. 2017), we model the available water that can be released for hydropower generation using reservoir specifications and according to the inflow time series generated by the previous hydrological model. Releases are specified for each month of the year, as well as reservoir level and spillage. Storage dynamics are simulated using the laws of mass balance:

$$
\begin{gathered}
S_{t}=S_{t-1}+Q_{t}+V_{t}^{*}-V_{t} \\
0 \leq S_{t} \leq S_{\text {usable }} \\
V_{\text {min }} \leq V_{t} \leq V_{\text {max }}
\end{gathered}
$$

where $S_{t}$ in the reservoir storage in month $t, Q_{t}$ is the current period reservoir inflow, $V_{t}^{*}$ is the water release or spillage from an upstream hydropower dam (if any) and $V_{t}$ is the water release

\footnotetext{
${ }^{6}$ Notice that there is a lag time $\mathrm{m}$ between precipitation and runoff, which has been adjusted to obtain the best model fit.

${ }^{7}$ A categorical variable was inserted to improve regression fit and represent seasonal patterns, being $d_{2}=0$ for the dry season (from October to February) and $d_{2}=1$ for the wet season.
} 
volume to the turbines. $S_{\text {usable }}$ is the maximum usable storage of the reservoir, $V_{\max }$ is the maximum volume of water that can be released through the turbines for the hydropower station to work at maximum capacity in each period and $V_{\min }$ is the minimum release that must satisfy turbine operation, downstream hydropower stations requirements and environmental flows. Monthly hydropower production $E_{t}(\mathrm{MWh})$ and capacity factor $\mathrm{CF}$ are simulated as follows:

$$
\begin{aligned}
& E_{t}=\eta \cdot \rho \cdot g \cdot H \cdot V_{t} \\
& C F_{t}=E_{t} /(P \cdot T)
\end{aligned}
$$

where $\eta$ is plant efficiency, $\rho$ is the water density, $g$ is gravitational acceleration, $H$ is hydraulic head and $V_{t}$ is the inflow into the turbine. Efficiency $\eta$ accounts for turbine efficiency and friction losses, and is used as a calibration parameter. Hydraulic head considers penstock vertical head plus average dam height. In the capacity factor equation, $P$ is nominal capacity of the hydropower station and $T$ is number of hours in a month. We choose to assess the monthly capacity factor since hydroclimatic conditions are generally integrated into energy system models by exogenously defining the capacity factor of hydropower power generation technologies to characterise their availability according to inter-annual runoff seasonality (Gargiulo 2009; Kannan and Turton 2011; IFE 2013). Uncertainty in monthly hydropower production is inferred from the frequency distribution associated with the inflows obtained with GCM ensemble results and quantified by the magnitude of the standard deviation. Detailed mathematical formulation and validation results of the hydrological and hydropower model are provided in the Supplementary Material.

\section{Results and discussion}

We find that inter-GCM range of projections is extremely large, maximum deviations from the mean span from - 82\% for the GFDL-CM3 (GCM no. 17) in Agoyán to + 277\% for the IPSLCM5A-LR (GCM no. 32) in Minas San Francisco. Figure 2 shows the projected mean annual inflow percentage changes compared to the historic baseline for each GCM and the CMIP5 ensemble mean (last black column in Fig. 2). There is also considerable variability in the climate change signal among gauging stations, meaning that a GCM is not necessarily consistent with increasing or decreasing values for different regions in a same scenario. The GISS-E2-R p2 (GCM no. 25), for example, suggests mean annual increases in Marcel Laniado, Minas San Francisco, Paute and Agoyán but decreases for Toachi Pilatón and Coca Codo Sinclair. In general, for the six gauging stations, out of 40 GCMs, 22 GCMs simulate an increase in mean annual discharge, the remaining 18 projecting decreases. This coincides with the ensemble mean projecting an increase in mean annual discharge since there are more models that agree on increase compared to decrease. However, given that all GCMs are considered equiprobable, this does not entail that there is a higher probability of increased inflow (Smith and Petersen 2014).

Seasonal watershed characteristics are maintained by most of the GCMs. Figure 3 presents results of the season inflow assessment. Forcing the conceptual hydrological model with CMIP5 ensemble mean shows slightly higher inflow values than those of the baseline. Uncertainty is greatest in the wet season, with some GCMs doubling or tripling the baseline inflow but others remaining closer to the baseline values. Analysing results according to wet and dry seasons, we find that during the wet season, $62 \%$ of the GCMs agrees on increases, 

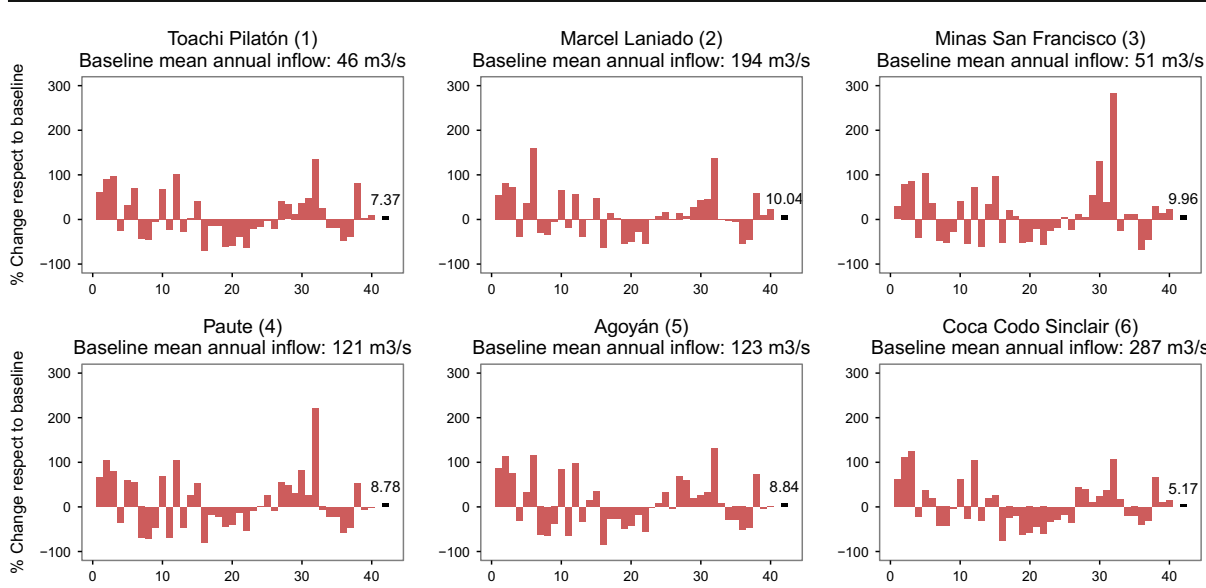

Fig. 2 Percentage change in the mean annual inflow at Ecuador's major hydropower stations. Results are given for the period 2071-2100, compared to the baseline 1971-2000, for each GCM under scenario RCP4.5 and the ensemble mean (black bar). GCMs are ordered according to Table 2 in the online resource

while during the dry season, 55\% of GCMs agree on decreases of inflow. This corroborates the prediction for the region having wetter wet seasons and drier dry seasons under climate change (Kundzewicz et al. 2007).

Regarding electricity generation, we find that capacity factors follow seasonal inflow patterns (compare to Fig. 3) and its variation range depends on storage and operational characteristics of the respective hydropower station. Figure 4 presents the capacity factors for historic, CMIP5 ensemble mean and the \pm 1 SD (error bars). Cascading hydropower stations in the same river have been aggregated given that they usually are considered as one integrated operation system. A + 1SD optimistic scenario increases the monthly capacity factors (85-89\%); however, the - 1SD presents a more critical situation: monthly capacity
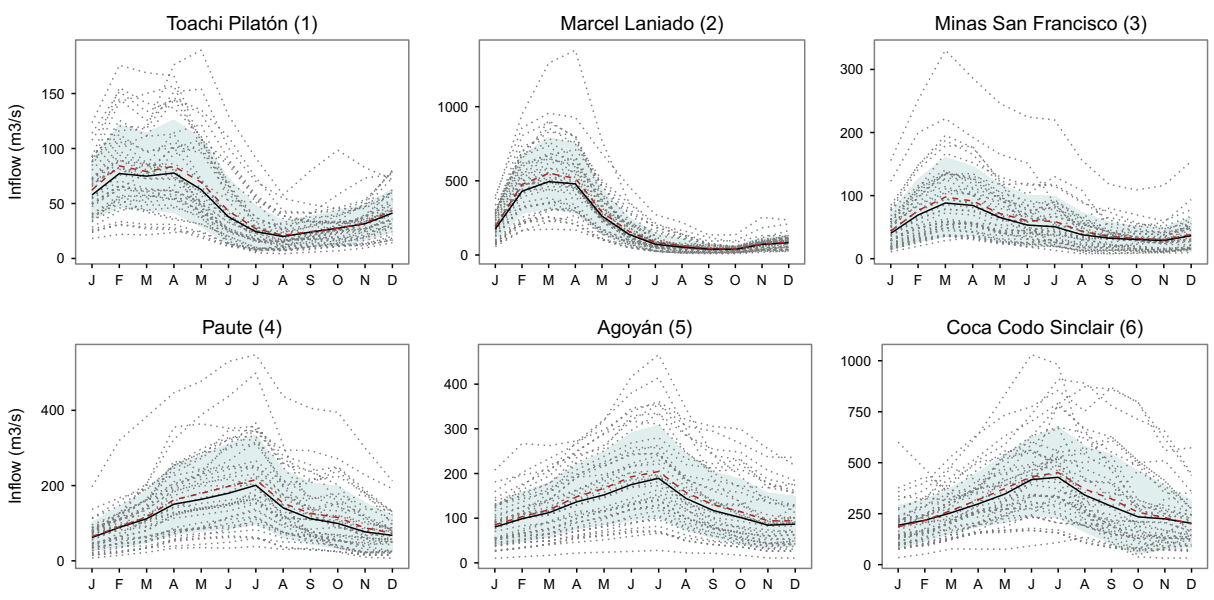

CMIP5 Ensemble mean + SD

Fig. 3 River inflow regimes for gauging stations at Ecuador's major hydropower stations. The historic baseline, each GCM and the CMIP5 ensemble mean under the RCP4.5 scenario for the 2071-2100 period is shown. The shaded band represents the standard deviation 

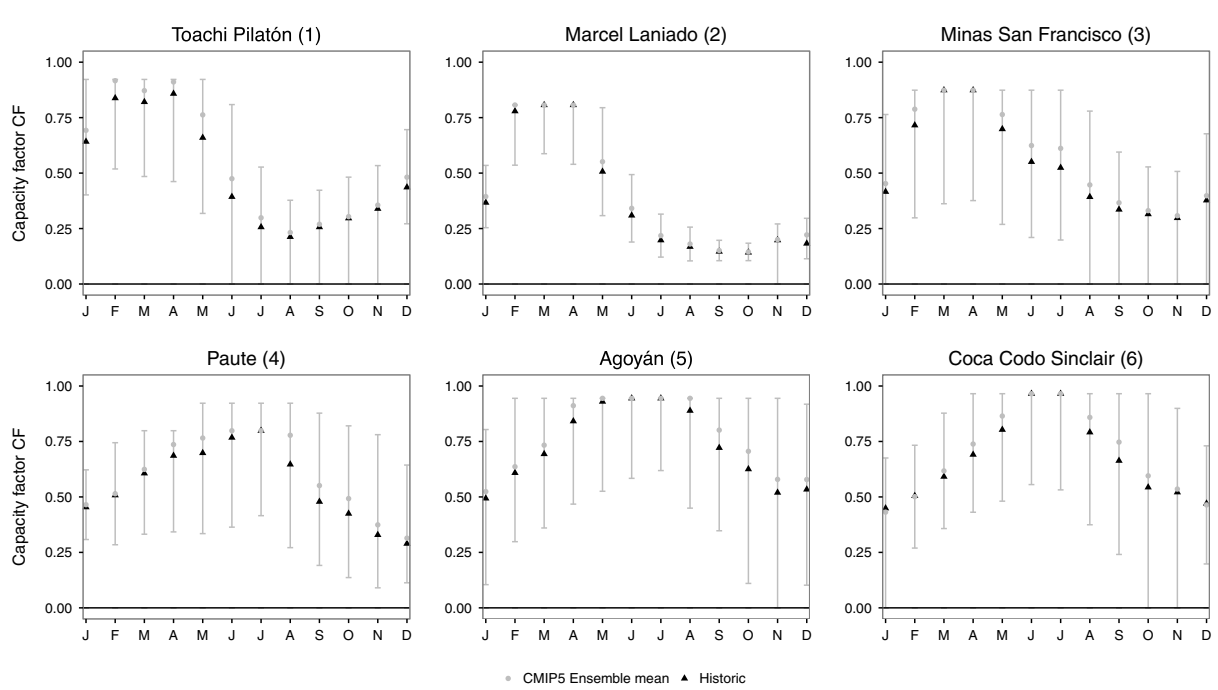

Fig. 4 Mean monthly capacity factors for Ecuador's major hydropower stations. The \pm 1 standard deviation is shown by the probability space parameterised with the CMIP5 ensemble under RCP4.5 for the period 2071-2100

factor dropping to a value of $0 \%$ during the dry season, namely for the stations that have small regulation capacity i.e. Coca Codo Sinclair, Minas San Francisco and Toachi Pilatón. Marcel Laniado which has a large reservoir presents less sensitivity to changes although in the - 1SD drops likewise to zero at the peak of the dry period in November. Figure 5 presents results for electricity generation for the aggregated hydropower system which has a total installed capacity of $4368 \mathrm{MW}$. The + 1SD scenario presents an overall higher electricity output throughout the year; the wet season (March to August) presents a $15 \%$ average increase, while the dry season presents an average increase of $46 \%$. In contrast, the -1 SD presents an average reduction of $-50 \%$ during the wet season and of $-76 \%$ for the dry season. Stations: Coca Codo Sinclair, Toachi Pilatón, and Minas San Francisco do not have any output at all in the dry season for the - 1SD scenario. Paute and Agoyán maintain output in the - 1SD dry scenario due to their regulation capacities. Marcel Laniado seems less affected by inflow variations due to its large reservoir. Table 1 presents results at the annual level and percentage deviations from annual observed generation values for the aggregated hydropower system (22801 GWh), showing a $6 \%$ increase $(1408 \mathrm{GWh})$ for the ensemble mean, $39 \%$ increase $(800 \mathrm{GWh})$ for a
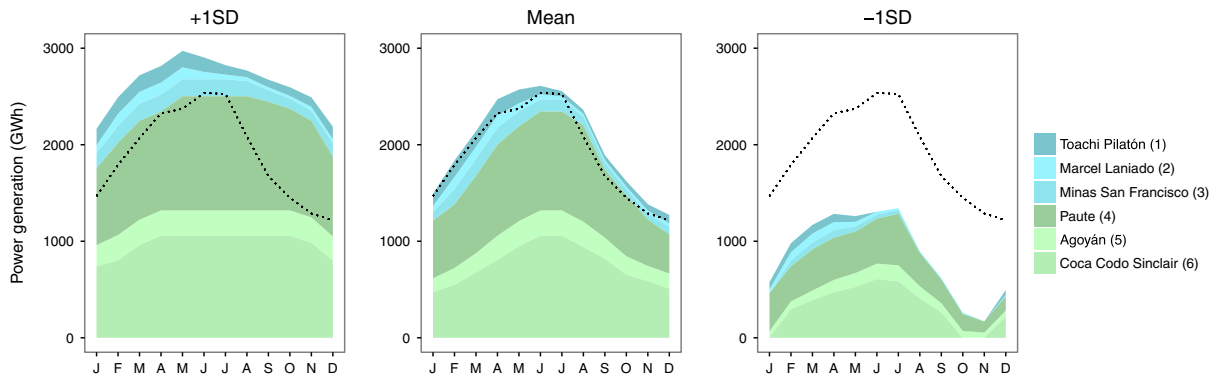

Fig. 5 Typical seasonal power generation for selected hydropower stations considering mean and standard deviations according to the RCP4.5 of the CMIP5 ensemble for the 2071-2100 period. The dotted line is the aggregated historical generation. Amazon watershed (in green) than the Pacific watershed (in blue) 
Table 1 Annual generation output changes for the RCP4.5 ensemble mean, + 1SD and - 1SD. Simulated annual generation is for period 2071-2100

\begin{tabular}{|c|c|c|c|c|c|c|c|c|}
\hline \multirow[t]{2}{*}{ No. } & \multirow[t]{2}{*}{ River } & \multirow[t]{2}{*}{$\begin{array}{l}\text { Hydropower } \\
\text { stations }^{\text {a }}\end{array}$} & \multirow{2}{*}{$\begin{array}{l}\text { Installed } \\
\text { capacity } \\
(\mathrm{MW})\end{array}$} & \multirow{2}{*}{$\begin{array}{l}\text { Usable } \\
\text { storage } \\
\left(\mathrm{Hm}^{3}\right)\end{array}$} & \multirow{2}{*}{$\begin{array}{l}\text { Observed } \\
\text { generation } \\
\text { (GWh/year) }\end{array}$} & \multicolumn{3}{|c|}{$\begin{array}{l}\text { Simulated annual } \\
\text { generation (GWh/year) }\end{array}$} \\
\hline & & & & & & $-1 \mathrm{SD}$ & $\begin{array}{l}\text { Ensemble } \\
\text { mean }\end{array}$ & $+1 \mathrm{SD}$ \\
\hline \multicolumn{9}{|c|}{ Pacific watershed } \\
\hline 1 & Toachi & Toachi Pilatón ${ }^{\mathrm{b}}$ & 255 & 0 & 1086 & $-59 \% \downarrow$ & $9 \% \uparrow$ & $41 \% \uparrow$ \\
\hline 2 & Daule & Marcel Laniado & 213 & 1733 & 717 & $-36 \% \downarrow$ & $5 \% \uparrow$ & $25 \% \uparrow$ \\
\hline 3 & Jubones & $\begin{array}{l}\text { Minas San } \\
\text { Francisco }^{\mathrm{b}}\end{array}$ & 275 & 10 & 1213 & $-73 \% \downarrow$ & $7 \% \uparrow$ & $43 \% \uparrow$ \\
\hline \multicolumn{9}{|c|}{ Amazon watershed } \\
\hline 4 & Paute & Paute & 1757 & 346 & 8314 & $-52 \% \downarrow$ & $8 \% \uparrow$ & $46 \% \uparrow$ \\
\hline 5 & Pastaza & Agoyán & 368 & 0.8 & 2325 & $-48 \% \downarrow$ & $6 \% \uparrow$ & $29 \% \uparrow$ \\
\hline 6 & Coca & Coca Codo Sinclair & 1500 & 0 & 7167 & $-57 \% \downarrow$ & $4 \% \uparrow$ & $34 \% \uparrow$ \\
\hline \multicolumn{3}{|c|}{ Total system } & 4368 & & 20,822 & $-55 \% \downarrow$ & $6 \% \uparrow$ & $39 \% \uparrow$ \\
\hline
\end{tabular}

${ }^{\text {a }}$ Cascading hydropower systems have been aggregated: Toachi Pilatón (Toachi 205 MW and Pilatón 50 MW), Paute (Mazar 170 MW, Molino, 1100 MW and Sopladora 487 MW) and Agoyán (Agoyán 156 MW and San Francisco 213 MW)

${ }^{\mathrm{b}}$ Still under construction and expected to enter operation in 2017. Estimated annual generation from feasibility studies was used

$+1 \mathrm{SD}$ scenario, while a significant reduction of $-55 \%(-12400 \mathrm{GWh})$ for the $-1 \mathrm{SD}$ scenario. These results provide statistical information which allows the use of alternative methods for addressing uncertainty in long-term energy planning analysis. Standard deviation is chosen since it has been used as a measure for uncertainty in risk analysis approaches and investment portfolio analysis for the power sector (Awerbuch and Yang 2007; Krey and Zweifel 2008; Vithayasrichareon and MacGill 2012). Traditionally, renewable energy sources, including hydropower, are considered of null or low risk in terms of operation price compared to thermal sources that depend on fuels with volatile prices. However, hydropower with its long-lived infrastructure has an inherent risk of experimenting high or low runoff outcome due to long-term climate variations. In this analysis, we have simulated the output of each hydropower station in isolation and work at maximum capacity when water is available. However, the operation of dams and hydropower stations depends not only on the availability of water but also on their interaction with the rest of the power system, for example, optimised real operation may sacrifice base load dispatch and reserve water for peak demand hours when electricity prices are high (IFE 2013; Yi Ng et al. 2017).

Our approach based on simulated hydropower production driven by changes on runoff due to climate change variations has some limitations. First, the use of the delta method to estimate the percentage changes of climate variables compared to a historic baseline entails assumptions about the nature of the changes, including a lack of change in the variability and spatial patters of climate (NORDEN 2010). The lack of meteorological data and high variability of the climate system in the Tropical Andes region complicate the use of more complex downscaling methods (Buytaert et al. 2010) and using downscaled information can be no more reliable than the climate model simulation that underlies it; more detail does not automatically imply better information (Taylor et al. 2012). Reliance on climate data from KNMI and downscaling from $0.5^{\circ}$ grids may also result in incorrect inflows for regions with complex topography where there are sharp changes in rainfall and runoff over short distances. Second, ceteris paribus was 
assumed in this study in terms of other hydrological variables that can affect runoff in the longterm, e.g. land use and vegetation cover, upstream water use for agricultural or industrial purposes, which should be of concern specially for changes in seasonal patterns. However, most of the assessed capacity and future hydropower potential in Ecuador are on the eastern slopes of the Andes facing the Amazon flood plain where currently less than $4 \%$ of the country's population lives (INEC 2012). Finally, the distribution of a climate ensemble is not a true probability distribution but instead an expert judgement with respect to potential future climatic conditions (Moss et al. 2010) and therefore assigning probability statistics to them might be misleading (Taylor et al. 2012; Collins and Knutti 2013). Nonetheless, for the purpose of analysing impacts of climate change, GCMs are still the only credible tools currently available to simulate the physical processes that determine global climate, and are used as a basis for assessing climate change impacts on natural and human systems, especially when there is a need to parameterise the probability space (Schaeffer et al. 2013a; Parkinson and Djilali 2015).

\section{Conclusions and policy implications}

The results of this study show that the long-term projected changes in unregulated inflow into hydropower stations encompass a wide range, dominated by the large differences in interGCM precipitation projections. The CMIP5 ensemble mean projects a slight increase in total/ mean annual inflow into Ecuador's hydropower stations towards the end of the century. However, when using the CMIP5 ensemble projections to characterise the probability space, the assessment of the seasonal patterns indicates that the country will experience wetter wet seasons and drier dry seasons, leading to large variations of hydropower annual output. Shortfalls in hydropower production would result in either reduced available electrical energy for consumers or, more likely, a temporary shift in the means of power generation. Ecuador's plans to become a net exporter of hydroelectric power to neighbouring Colombia, Peru and even Chile will need to be closely monitored given the loss of revenues and the projected increase in domestic demand that will need to augment supplies from alternative resources, including renewables or oil and gas fired plants. The opposite is also plausible; heavy rains could contribute to increased hydropower output, leading to reduced energy costs and surplus for exports (if international transmission infrastructure were available). The scale of these impacts is likely to depend on both the magnitude of the hydropower production windfall or shortfall and the relative importance of hydropower in the energy matrix. Hydropower stations with storage capabilities show less sensitivity to inflow changes compared to runoff facilities, although extreme dry scenarios will leave any storage capacities ineffective. Therefore, dambased hydropower will have only certain climate-change-risk-control advantage compared to runoff stations; however, they will need larger investments and cause larger social and environmental impacts.

Future research should point in the direction of methodologies that include the results and uncertainty of climate change projection ensembles in combination with energy system models that can capture hydropower interaction with the rest of the energy system. Complimentary future research on the role of the El Niño Southern Oscillation (ENSO), which has large impacts in this region, and its changes in frequency, intensity and duration, will help also to define a better picture of vulnerability hotspots where hydropower and other renewable energy sources are critically exposed to inter-annual climate variability. Such studies would 
inform decision makers of necessary investments needed to ensure energy security in the face of climate change. For Ecuador, a more robust long-term electricity should focus on an appropriate diversification of generating technologies. The share of hydropower particularly large runoff facilities must decrease rapidly, while policy support should promote an increase in non-conventional renewables.

Acknowledgements Profound appreciation is extended to the Ecuadorian Secretariat of Higher Education, Science, Technology and Innovation (SENESCYT) for providing monetary support to the first author for his doctoral studies at UCL Energy Institute.

Open Access This article is distributed under the terms of the Creative Commons Attribution 4.0 International License (http://creativecommons.org/licenses/by/4.0/), which permits unrestricted use, distribution, and reproduction in any medium, provided you give appropriate credit to the original author(s) and the source, provide a link to the Creative Commons license, and indicate if changes were made.

\section{References}

ARCONEL (2015) Plan Maestro de Electricidad - Expansion de la Generacion

ARCONEL (2016) Balance Nacional Electrico Noviembre 2016. http://www.regulacionelectrica.gob. ec/estadistica-del-sector-electrico/balance-nacional/. Accessed 1 Feb 2017

Arnold JG, Srinivasan R, Muttiah RS, Williams JR (1998) Large area hydrologic modeling and assessment part I: model development. J Am Water Resour Assoc 34:73-89. doi:10.1111/j.1752-1688.1998.tb05961.x

Awerbuch S, Yang S (2007) Efficient electricity generating portfolios for Europe: maximising energy security and climate change mitigation. EIB Pap 12:8-37 ISSN 0257-7755

Babur M, Babel MS, Shrestha S et al (2016) Assessment of climate change impact on reservoir inflows using multi climate-models under RCPs-the case of Mangla Dam in Pakistan. Water. doi:10.3390/w8090389

Bates B, Kundzewicz ZW, Wu S, Palutikof J (2008) Climate change and water. Technical paper of the Intergovernmental Panel on Climate Change. Intergovernmental Panel on Climate Change (IPCC)

Buytaert W, Vuille M, Dewulf a et al (2010) Uncertainties in climate change projections and regional downscaling in the tropical Andes: implications for water resources management. Hydrol Earth Syst Sci 14:12471258. doi:10.5194/hess-14-1247-2010

Buytaert W, Cuesta-Camacho F, Tobón C (2011) Potential impacts of climate change on the environmental services of humid tropical alpine regions. Glob Ecol Biogeogr 20:19-33. doi:10.1111/j.1466-8238.2010.00585.x

Célleri R (2007) Rainfall variability and rainfall-runoff dynamics in the Paute River Basin-Southern Ecuadorian Andes. Katholieke Universiteit Leuven

CEPAL (2012) Análisis de Vulnerabilidad del Sector Hidroeléctrico frente a escenarios futuros de cambio climatico en Chile. Santiago, Chile

Cisneros J, BE TO, Arnell NW, et al (2014) Freshwater resources. In: Climate change 2014: impacts, adaptation, and vulnerability. Part A: global and sectoral aspects. Contribution of working group II to the fifth assessment report of the Intergovernmental Panel on Climate Change [Field, C.B., V.R

Collins M, Knutti R (2013) Long-term climate change: projections, commitments and irreversibility 2013: The physical science basis. Contribution of working group I to the fifth assessment report of the Intergovernmental Panel on Climate Change

De Lucena AFP, Szklo AS, Schaeffer R et al (2009) The vulnerability of renewable energy to climate change in Brazil. Energy Policy 37:879-889. doi:10.1016/j.enpol.2008.10.029

De Lucena A, Schaeffer R, Szklo A (2010) Least-cost adaptation options for global climate change impacts on the Brazilian electric power system. Glob Environ Chang 20:342-350. doi:10.1016/j.gloenvcha.2010.01.004

DOE (2015) Climate change and the U.S. energy sector: regional vulnerabilities and resilience solutions

El Comercio (2016) Cuatro turbinas del Coca-Codo comenzaron a entregar energía en firme | El Comercio. http:/www.elcomercio.com/actualidad/turbinas-cocacodosinclair-jorgeglas-energia.html. Accessed 24 Oct 2016

Escobar M, López FF, Clark V (2011) Energy-water-climate planning for development without carbon in Latin America and the Caribbean

Espinoza Villar JC, Ronchail J, Guyot JL et al (2009) Spatio-temporal rainfall variability in the Amazon basin countries (Brazil, Peru, Bolivia, Colombia, and Ecuador). Int J Climatol 29:1574-1594. doi:10.1002/joc.1791

Finer M, Jenkins CN (2012) Proliferation of hydroelectric dams in the Andean Amazon and implications for Andes-Amazon connectivity. PLoS One 7:e35126. doi:10.1371/journal.pone.0035126 
Fowler HJ, Blenkinsop S, Tebaldi C (2007) Linking climate change modelling to impacts studies: recent advances in downscaling techniques for hydrological modelling. Int J Climatol 27:1547-1578. doi:10.1002/joc. 1556

Gargiulo M (2009) Getting started with TIMES-VEDA

Grijsen J (2014) Understanding the impact of climate change on hydropower: the case of Cameroon

Hamlet AF, Lee S-Y, Mickelson KEB, Elsner MM (2010) Effects of projected climate change on energy supply and demand in the Pacific Northwest and Washington State. Clim Chang 102:103-128. doi:10.1007/s10584010-9857-y

Harris I, Jones PD, Osborn TJ, Lister DH (2014) Updated high-resolution grids of monthly climatic observations - the CRU TS3.10 dataset. Int J Climatol 34:623-642. doi:10.1002/joc.3711

Hay LE, Clark MP, Wilby RL et al (2002) Use of regional climate model output for hydrologic simulations. J Hydrometeorol 3:571-590. doi:10.1175/1525-7541(2002)003<0571:UORCMO>2.0.CO;2

Ho JT, Thompson JR, Brierley C (2015) Projections of hydrology in the Tocantins-Araguaia Basin, Brazil: uncertainty assessment using the CMIP5 ensemble. Hydrol Sci J 6667:150603015228007. doi:10.1080 /02626667.2015.1057513

IFE (2013) TIMES-Norway Model Documentation

INEC (2012) Estandisticas Nacionales

IPCC (2014) Climate change 2014: impacts, adaptation and vulnerability - contributions of the working group II to the fifth assessment report - summary for policy makers

Jones RN, Chiew FHS, Boughton WC, Zhang L (2006) Estimating the sensitivity of mean annual runoff to climate change using selected hydrological models. Adv Water Resour 29:1419-1429. doi:10.1016/j. advwatres.2005.11.001

Kannan R, Turton H (2011) Documentation on the development of the Swiss TIMES Electricity Model (STEM-E)

Kaser G, Juen I, Georges C et al (2003) The impact of glaciers on the runoff and the reconstruction of mass balance history from hydrological data in the tropical Cordillera Blanca, Perú. J Hydrol 282:130-144. doi:10.1016/S0022-1694(03)00259-2

Kaser G, Grosshauser M, Marzeion B (2010) Contribution potential of glaciers to water availability in different climate regimes. Proc Natl Acad Sci U S A 107:20223-20227. doi:10.1073/pnas.1008162107

Krey B, Zweifel P (2008) Efficient electricity portfolios for the United States and Switzerland: an investor view

Kundzewicz, Mata, Arnel, et al (2007) Freshwater resources and their management. In: Climate change 2007: impacts, adaptation and vulnerability. pp 173-210

Lind A, Rosenberg E, Seljom P, Espegren K (2013) The impact of climate change on the renewable energy production in Norway. In: 2013 International Energy Workshop

Liu X, Tang Q, Voisin N, Cui H (2016) Projected impacts of climate change on hydropower potential in China. 20:3343-3359. doi: 10.5194/hess-20-3343-2016

Madani K, Lund JR (2010) Estimated impacts of climate warming on California's high-elevation hydropower. Clim Chang 102:521-538. doi:10.1007/s10584-009-9750-8

MICSE (2016) Agenda Nacional de Energia

Moss RH, Edmonds JA, Hibbard KA et al (2010) The next generation of scenarios for climate change research and assessment. Nature 463:747-756. doi:10.1038/nature08823

NORDEN (2010) Conference on future climate and renewable energy: impacts, risks and adaptation. In: Conference on future climate and renewable energy: impacts, risks and adaptation

van Oldenborgh GJ, Collins M, Arblaster J, et al (2013) Annex I: atlas of global and regional climate projections

Parkinson S, Djilali N (2015) Robust response to hydro-climatic change in electricity generation planning. Clim Chang:1-15. doi:10.1007/s10584-015-1359-5

Schaeffer R, Szklo A, De Lucena A et al (2013a) The vulnerable Amazon: the impact of climate change on the untapped potential of hydropower systems. IEEE Power Energy Mag 11:22-31. doi:10.1109 /MPE.2013.2245584

Schaeffer, Szklo, Lucena, et al (2013b) The impact of climate change on the untapped potential of hydropower systems

Shrestha S, Bajracharya AR, Babel MS (2016) Assessment of risks due to climate change for the upper Tamakoshi hydropower project in Nepal. Clim Risk Manag 14:27-41. doi:10.1016/j.crm.2016.08.002

Smith LA, Petersen AC (2014) Variations on reliability: connecting climate predictions to climate policy. Error Uncertain Sci Pract:137-156

Taylor KE, Stouffer RJ, Meehl GA (2012) An overview of CMIP5 and the experiment design. Bull Am Meteorol Soc 93:485-498. doi:10.1175/BAMS-D-11-00094.1

Thomson AM, Calvin KV, Smith SJ et al (2011) RCP4.5: a pathway for stabilization of radiative forcing by 2100. Clim Chang 109:77-94. doi:10.1007/s10584-011-0151-4

Trouet V, Van Oldenborgh GJ (2013) KNMI climate explorer: a web-based research tool for high-resolution paleoclimatology. Tree-Ring Res 69:3-13. doi:10.3959/1536-1098-69.1.3 
Vergara W, Deeb AM, Valencia AM et al (2007) Economic impacts of rapid glacier retreat in the Andes. EOS Trans Am Geophys Union 88:261. doi:10.1029/2007EO250001

Vetter T, Huang S, Aich V et al (2015) Multi-model climate impact assessment and intercomparison for three large-scale river basins on three continents. Earth Syst Dyn 6:17-43. doi:10.5194/esd-6-17-2015

Vithayasrichareon P, MacGill IF (2012) Portfolio assessments for future generation investment in newly industrializing countries - a case study of Thailand. Energy 44:1044-1058. doi:10.1016/j. energy.2012.04.042

van Vliet MTH, Wiberg D, Leduc S, Riahi K (2016) Power-generation system vulnerability and adaptation to changes in climate and water resources-supplementary information. Nat Clim Chang. doi:10.1038 /nclimate2903

Yi Ng J, Turner S, Galelli S (2017) Influence of El Nino Southern Oscillation on global hydropower production Zambrano-Barragen P (2012) The role of the state in large-scale hydropower development. Perspectives from Chile, Ecuador, and Peru. MASSACHUSETTS INSTITUTE OF TECHNOLOGY 